\section{Brain, Behavior and Evolution}

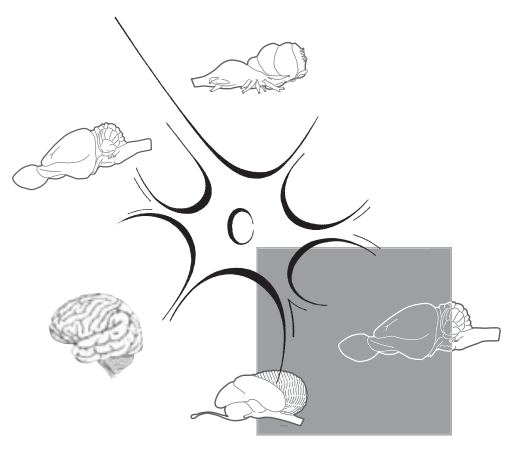

The present response, as well as previous debates regarding the late-equalslarge hypothesis [e.g. in Finlay et al., 2001, and responses therein], suggests as a main issue of debate the information content in a regression analysis. To Finlay et al. a high correlation suggests a strikingly conservative pattern, which is regularly invoked in the 15-year corpus of work that they refer to (and which I briefly reviewed). To others, the variation behind even a very good fit (which is easily overlooked when the data are - perfectly appropriately - log transformed) does not allow this conclusion [de Winter and Oxnard, 2001; Barton, 2007].

Finlay et al. do not represent my analysis as I conducted it - I certainly did not apply human-scale values to hamsters. I assessed model prediction accuracy as it relates to the confidence of event placement in an actual sequence. For this, I investigated for each species how many events occur around an arbitrary event in the sequence median within the smallest confidence limit for any event in that species - a very conservative estimate. This showed that event positioning is far from predictable. An event can occur numerous sequence positions around its predicted position (20-25\% of all positions on either side of the median event) even within this narrow confidence limit. Similarly, a leave-one-out analysis with such generous prediction leeway will return a good fit, but not reliable positioning.

Highlights and Perspectives on Evolutionary Neuroscience

Published online: March 8, 2010 DOI: $10.1159 / 000295351$

\title{
Author's Reply to: Late Still Equals Large
}

\author{
Vera Weisbecker \\ Earth Sciences, Cambridge University, Cambridge, UK
}

I am not sure why Finlay et al. suggest that I somehow relate the flow of information to contingency. The dominance of 3 structures (cortex, thalamus, visual system) in the developmental dataset increases the likelihood of contingency because later events in a structure depend on earlier ones. This effect would be smaller if a greater diversity of ontogenetically discrete systems were considered.

Despite the low predictability of the neurogenetic sequence, Finlay et al. convincingly demonstrated that the general tendency of neurogenetic events to occur early or late influences the evolution of scaling in the discrete subunits they worked on (such as thalamus, cortical layers, or limbic system). However, 'late equals large' originally referred to the scaling of complex anatomical brain partitions (e.g. neocortex), and is invoked in this context [e.g. Finlay et al., 2001; Finlay, 2008]. The cerebellum was indeed a bad example, but sufficient representation exists for a number of brain partitions in the neurogenetic dataset to assess scaling/ timing correspondence. This approach is justified because, due to exponential scaling, the steepest-scaling components of any arbitrary assembly of subunits (which should develop latest) will dominate this assembly's scaling with brain size. In particular, low-scaling components with high development scale scores (hippocampus/ schizocortex) and high-scaling components whose dominant components score low on the developmental scale (e.g. the caudoputamen of the striatum) are not predicted by 'late equals large'.

I agree that the search of commonalities is a worthwhile undertaking to contextualize evolutionary and comparative biomedical research. However, evolutionary patterns related to heterochrony are more reliably assessed based on sequence position changes (e.g. of the limbic system in primates), rather than deviations from regression that includes the heterochronic data. My vote therefore remains with a phylogenetically informed, heterochronyfocused case-by-case analysis.

\section{References}

-Barton RA (2007): Evolutionary specialization in mammalian cortical structure. J Evol Biol 20:1504-1511.

De Winter W, Oxnard CE (2001): Evolutionary radiations and convergences in the structural organization of mammalian brains. Nature 409:710-714.

Finlay BL (2008): Brain evolution: developmental constraints and relative developmental growth; in Squire LR (ed): Encyclopedia of Neuroscience (online version). Amsterdam, Elsevier, pp 337-345.

Finlay BL, Darlington RB, Nicastro N (2001): Developmental structure in brain evolution. Behav Brain Sci 24:263-308.

Finlay BL, Clancy B, Darlington RB (2010): Late Still Equals Large. Brain Behav Evol 75: 4-6.

\section{KARGER}

Fax +4161306 1234 E-Mail karger@karger.ch www.karger.com
(C) 2010 S. Karger AG, Base 0006-8977/10/0751-0007\$26.00/0

Accessible online at: www.karger.com/bbe
Vera Weisbecker

Earth Sciences, Cambridge University

Downing Street

Cambridge CB2 3EQ (UK)

Tel. +44 1223768 329, Fax +44 1223333 450, E-Mail vw248@cam.ac.uk 